\title{
Effects of temperature and population density on von Bertalanffy growth parameters in Atlantic herring: a macro-ecological analysis
}

\author{
Thomas Brunel* ${ }^{*}$ Mark Dickey-Collas \\ Wageningen IMARES, Institute for Marine Resources and Ecosystem Studies, PO Box 68, \\ 1970 AB IJmuiden, The Netherlands
}

\begin{abstract}
The effect of temperature and population density on the growth of Atlantic herring Clupea harengus was studied using a comparative approach applied to 15 North Atlantic populations. The von Bertalanffy (VB) equation was applied to describe mean growth of individuals in each population, both averaged over the whole period studied and for each cohort. Water temperature was a determinant factor for herring growth at the species level: North Atlantic herring in cold water areas exhibited a lower growth coefficient $(k)$, longer lifespan and a higher asymptotic weight $\left(w_{\text {inf }}\right)$ than those living in warmer water. The average $W_{\text {inf }}$ of herring was positively correlated to the density of biomass of that population. This relationship was most likely due to the negative correlation found between population density and mean temperature. At the within-population level, when looking at the temporal variability in growth parameters amongst cohorts, $w_{\text {inf }}$ was still negatively correlated to temperature, but the positive correlation between $k$ and temperature was no longer significant. In a single population, the temperature range is probably too narrow to have an identifiable effect on growth. The effect may be confounded by other factors such as density dependence. On the basis of this macroecological pattern, global warming should enhance growth of the youngest age-classes, but reduce the growth of older individuals and shorten the lifespan of herring.
\end{abstract}

KEY WORDS: von Bertalanffy equation · Temperature effects · Density dependence $\cdot$ Meta-analysis · Weight-at-age $\cdot$ Climate $\cdot$ Comparative approach

Resale or republication not permitted without written consent of the publisher

\section{INTRODUCTION}

Atlantic herring Clupea harengus supports one of the largest fisheries in the world (FAO 2007). Because of its long-time economic importance, the species has been well studied (Heincke 1898, Sinclair \& Solemdal 1988, Dickey-Collas et al. 2009). Most studies are population-specific. To understand the likely effect of climate change on a fish species, the dynamics of populations across its spatial distribution must be considered. Comparative species-level studies on cod Gadus morhua have revealed patterns in the effect of temperature on growth (Brander 1995) and recruitment (Planque \& Fredou 1999). These patterns can be used to model the species' responses to climate change (Clark et al. 2003, Drinkwater 2005).
Comparative approaches are based on the idea that the range of environmental conditions experienced by a given population is small, making their influence difficult to detect. Pooling data from a number of populations broadens the range of conditions and makes it more likely to detect general patterns (Brander 1995, Brunel \& Boucher 2006). Hence, in a widely distributed fish species with a large phenotypic plasticity such as herring (Geffen 2009), a comparative approach beyond population-specific studies is required.

In many species, weight-at-age differs considerably among populations and can vary substantially over time for a given population (Brander 1995). Growth and recruitment are key components of productivity. Changes in growth rate will modify the sustainability of a fishery (Brander 2007). Hence, identifying the 
mechanisms responsible for variations in growth rates in an exploited fish stock is important for understanding the population's dynamics and the potential for sustainable fisheries management.

The 2 main mechanisms proposed for explaining growth variability in fish populations are (1) densitydependent regulation, interpreted in this study as a decreased growth rate caused by the increased competition for food when population size is high (Beverton \& Holt 1957); and (2) fluctuations in environmental conditions, which affect growth indirectly by controlling the quantity and quality of food (Möllmann et al. 2005) or directly, by the effect of physical factors, such as temperature, on the rates of physiological processes associated with growth (Brett 1979, Houde 1989). These mechanisms interact.

There is evidence that both density dependence and temperature regulate growth in herring. Populationspecific studies have identified cases where density dependence has regulated the growth of individuals, especially in populations which have collapsed and recovered, e.g. in the North Sea (Burd 1984, Heath et al. 1997), on the Norwegian coast (Engelhard \& Heino 2004, Husebø et al. 2007), and in the Gulf of Maine/ Georges Bank population (Anthony \& Fogarty 1985, Melvin \& Stephenson 2007). However no evidence of density dependence regulation of individual growth has been detected for the Celtic Sea, the West of Scotland and the Scotian Shelf herring populations, despite major changes in population size (Sinclair et al. 1982, Molloy 1984, Saville et al. 1984). A positive relationship between temperature and the growth of juvenile herring has been found in populations where growth did not co-vary with population density, as in the East of Newfoundland (Moores \& Winters 1982) and Gulf of Maine / Georges Bank stock complex (Anthony \& Fogarty 1985). However as with the effect of population density, the effect of temperature on growth has not been observed in herring across all stocks.

The contrasting evidence for a density-dependent and/or an environmental control of herring growth indicates that the mechanisms vary between populations and may change in time, suggesting that no general rule exists. In such cases using a comparative approach across a large number of herring populations can help identify general patterns.

Most of the studies on herring growth focus on the variations in weight at a given age, and therefore do not describe the pattern of growth throughout the entire lifespan. Alternatively a growth model can be fitted and the variations in the model parameters can be analyzed. This approach was applied to cod (Taylor 1958) and a strong relationship was found between the mean temperature conditions and the growth parameters of the von Bertalanffy (VB) equation, with smaller asymptotic size and faster size increase towards the asymptotic value for cod living in warmer waters than for cod in colder waters. Pacific herring Clupea pallasi does not completely follow this pattern, as herring in the western populations exhibit a substantially higher asymptotic weight than those in the eastern populations (Hay et al. 2008). This west-east difference in growth matches a geographic pattern of genetic variation between eastern and western Pacific herring. However, looking only at eastern populations, asymptotic weight of herring increased with latitude (and is therefore inversely related to temperature), as in the case in Atlantic cod. Such an approach has never been used to analyze growth in Atlantic herring and the findings of Taylor (1958) are assumed to apply to herring, but no published study has confirmed this.

The present study investigated the effect of 2 factors, temperature and population density (as a proxy for the intensity of density dependence), on the VB growth parameters in herring from 15 populations of the North Atlantic. The analysis was performed at 2 levels. (1) The existence of a species-level pattern was investigated; the differences in average growth parameters among herring were related to the difference in average temperature and population density experienced by the stocks. (2) Within populations, the relationship between variations in growth parameters of the different cohorts and the variability of the conditions prevailing during the development of these cohorts was examined.

\section{MATERIALS AND METHODS}

Data. The variation in growth of herring was studied from 15 stocks - assumed to represent true populations - distributed throughout the North Atlantic, from the Gulf of Maine to Newfoundland in the west and from the Celtic Sea to the Barents Sea in the east (Fig. 1).

The 5 populations of Baltic herring Clupea harengus membras were not included in the analysis. Baltic herring is a subspecies of the Atlantic herring which inhabits the brackish waters of the Baltic Sea. Baltic herring populations show a significant degree of genetic differentiation from neighbouring populations (Bekkevold et al. 2005, Ruzzante et al. 2006), e.g. those of the North Sea, suggesting a strong structuring effect of environmental gradients such as salinity (Bekkevold et al. 2005).

Weight-at-age data were collected from recent NAFO and ICES herring stock-assessment reports (references in Table 1). For most of the populations, the weight-atage of herring was estimated from length measurements taken by each fishing country from their commercial catches (Table 1). Length-at-age data were then converted into weight-at-age using a weight-length relationship, which was estimated on a yearly basis using 


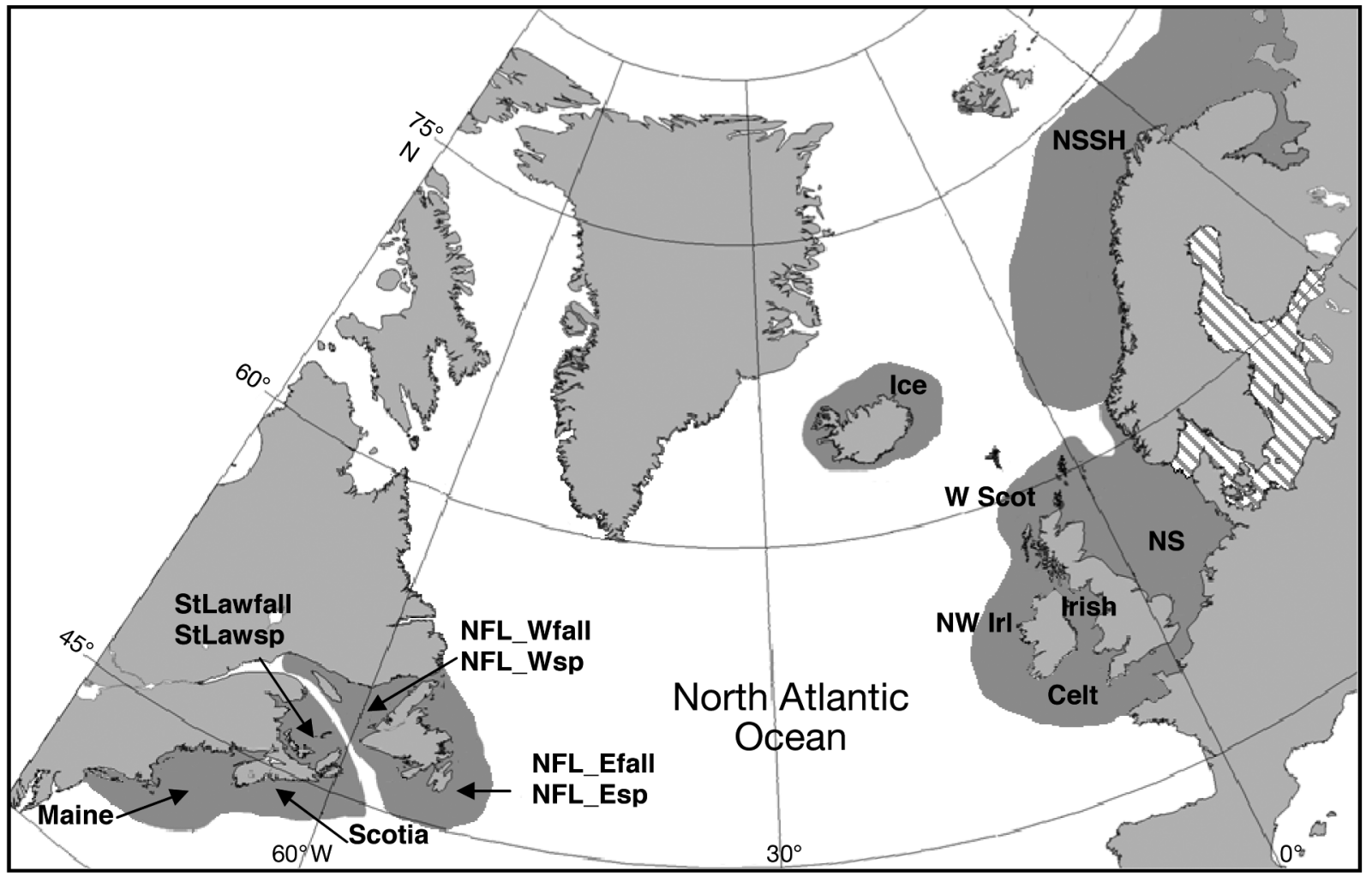

Fig. 1. Clupea harengus. Distribution of the main herring populations in the North Atlantic (grey areas); Baltic Sea, Skagerrak and Kattegat (striped) populations not included in the analysis. See Table 1 for definitions and sources

the weight measurements from subsamples also used to determine the age composition of the catch. The weightat-age from the different countries were then averaged by population for each quarter of the year. The data corresponding to the quarter where most of the spawning occurs was used for the stock assessment and this study. For some populations, weight-at-age of the herring came from weight measurements carried out during scientific surveys. Some of the time series of weight-at-age have periods of annually invariate estimates, generally near the beginning of the time series. These years were discarded from the time series. The length of the time series of weight-at-age of herring used in this study varied from 14 yr (1993-2006) for the West of Scotland herring to 46 yr (1961-2006) for Irish Sea herring.

The effect of population density on growth of herring may result from competition for food among individuals. Several authors (e.g. Burd 1984, Heath et al. 1997) used the total stock biomass (TSB) to study the effect of density dependence on growth, thereby assuming that the different age classes present in the population could potentially compete with each other. Whilst it might be more appropriate to consider density dependence in terms of numbers, these authors used biomass as a proxy for density. We continued to use this approach. Other authors (Husebø et al. 2007, Melvin \&
Stephenson 2007) considered that, since the different life stages of herring may live in different areas, competition is more likely to occur among individuals of the same cohort and therefore they used recruitment (RCT) to represent density.

Since this study compares the growth of herring from different populations, the difference in TSB (or RCT) among populations will reflect in the first place the difference in the area occupied by the populations. Therefore, the density of biomass of a population (densTSB, $\mathrm{km}^{-2}$ ) and the recruits density (densRCT, $10^{3}$ ind. $\mathrm{km}^{-2}$ ) were taken as proxies for the strength of the density dependent processes affecting herring in a population. These densities were defined as the ratio between TSB or RCT (same origin as the weight-at-age data) and the surface of the area occupied by the population. These areas were defined as areas of the sea bottom between 0 and $300 \mathrm{~m}$ in the NAFO or ICES fishing areas corresponding to each stock and were taken from Myers et al. (2001).

The effect of temperature on growth was studied using sea surface temperature (SST) as a proxy for the ambient temperature experienced by the fish. SST data were provided by the International Comprehensive Ocean-Atmosphere Data Set (ICOADS: http://icoads. noaa.gov) for the North Atlantic region for the period 


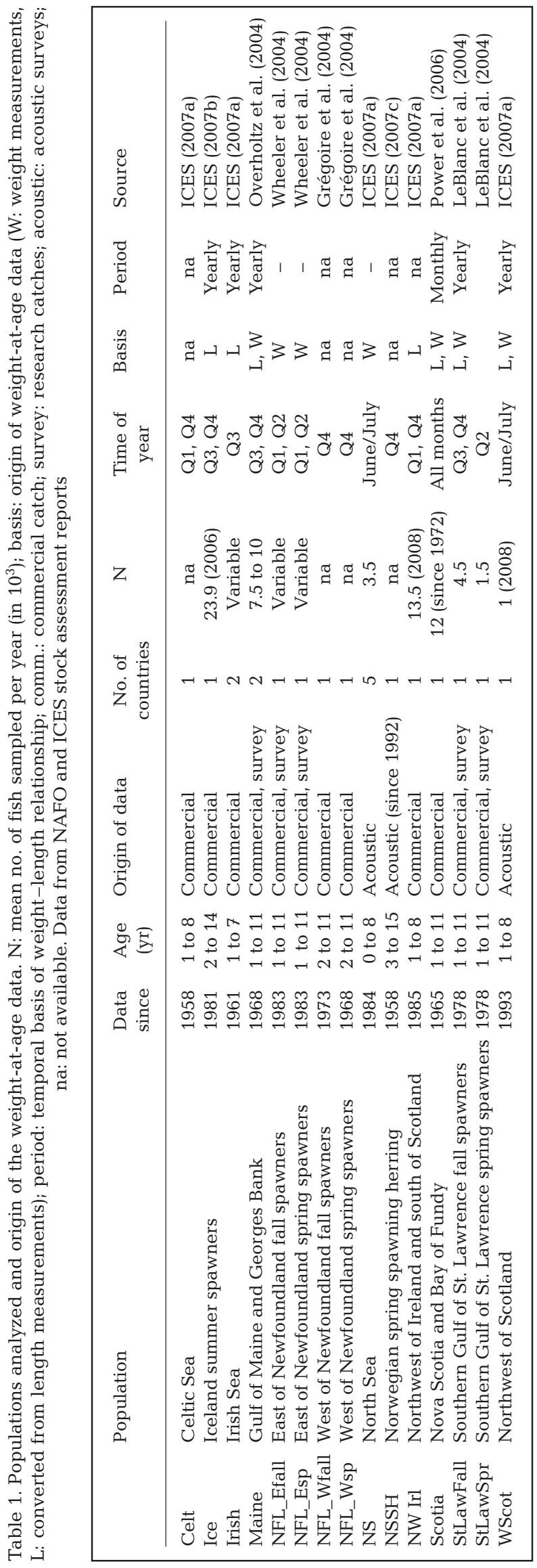

from 1958 to 2005. This dataset is a compilation of observational records from ships and buoys averaged monthly in $2^{\circ}$ latitude $\times 2^{\circ}$ longitude boxes. For each population, the annual mean temperature was calculated as the SST averaged over the 12 months and over all the $2^{\circ} \times 2^{\circ}$ boxes occupied by the population.

Growth analysis. Species level: The difference in growth of herring amongst the 15 populations was described by the VB growth equation, expressed in weight as a function of age (von Bertalanffy 1957). For the herring in each population $p o p$, the parameters of the population-specific growth curve were estimated by fitting the VB model to all the weights-at-age available for this population:

$$
W(t)_{y c, p o p}=w_{\text {inf pop }}\left\{1-\exp \left[-k_{\text {pop }}\left(t-t_{0, p o p}\right)\right]\right\}^{3}
$$

where, $w(t)_{y c, p o p}$ is weight at age $t$ for the year-class $y c$ in the population pop, $w_{\text {inf pop }}, k_{\text {pop }}$ and $t_{0 \text { pop }}$ are the 3 parameters of the VB equation for the population pop (asymptotic weight, growth coefficient, and theoretical age at weight $=0 \mathrm{~kg}$, respectively). Non-linear least square regression (nls function, $\mathrm{R}$ base statistical software; R Development Core Team 2006) was used to estimate the population-specific values of $w_{\text {inf pop }}, k_{\text {popr }}$

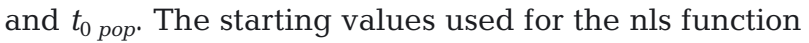
were $0.5,0.3$ and -0.5 for $w_{\text {inf pop }}, k_{\text {pop }}$ and $t_{0 \text { pop }}$ respectively, the same for all populations (preliminary fits of the model using a range of starting values all ended with the same solution).

In addition, the average lifespan, $A_{95}$ pop, defined as the age at which a fish would reach $95 \%$ of $W_{\text {inf }}$ (Taylor 1958), was computed for each population:

$$
A_{95 p o p}=t_{0}+\frac{2.966}{k_{p o p}}
$$

The effects of temperature and population density on growth at the species level were investigated by examining the relationship between VB growth parameters and lifespan of the herring in different populations, and mean temperature and population densities in the corresponding areas (densTSB and densRCT), calculated over the whole period studied.

Population level: The variability in growth between the different cohorts in a population was then examined. The VB growth equation was fitted separately on the weight-at-age data of each year-class to estimate cohort-specific growth parameters:

$$
w(t)_{y c, p o p}=w_{\text {inf } y c, p o p}\left\{1-\exp \left[-k_{y c, p o p}\left(t-t_{0, y c, p o p}\right)\right]\right\}^{3}
$$

where $w_{\text {inf } y c, p o p}, k_{y c, p o p}$ and $t_{0 \text { yc,pop }}$ are the parameters of the VB equation for the year-class $y c$ in the population pop. Only the year-classes for which weight-atage data were available for at least 6 ages were included in this analysis. For each population, the population level estimates of $W_{\text {inf pop }} k_{\text {pop }}$ and $t_{0 \text { pop }}$ were 
used as starting values in the lns function for the estimation of the cohort-specific parameters.

For each of these year-classes $y c$ of the population pop, the mean temperature experienced by the individuals, $\mathrm{SST}_{y c, p o p}$ was computed as the mean of the annual SST values experienced by that cohort. The average population densities experienced by the yearclass $y c$ during its lifespan, noted densTSB ${ }_{y c, p o p}$ and densRCT $\mathrm{T}_{Y c, p o p}$, were calculated in the same manner.

The relationships between cohort-specific growth parameters and average temperature or population density experienced by the cohort were tested by computing the correlation $r_{p o p}$ of the cohort-specific growth parameters ( $W_{\text {inf } y c, p o p}$ and $\left.k_{y c, p o p}\right)$ with the explanatory variables $\left(\mathrm{SST}_{y c, p o p}\right.$ densTSB $\mathrm{TC}_{y, p o p}$ and densRCT $\left.\mathrm{T}_{y c, p o p}\right)$. Biological and environmental time series are often autocorrelated. Autocorrelations violate the assumption of serial independence required for hypothesis testing, and tests of significance can be biased due to overestimation of the number of degrees of freedom (Pyper \& Peterman 1998). To compensate for these effects in our correlation tests, the number of degrees of freedom was corrected using the modified Chelton method as described in Pyper \& Peterman (1998):

$$
\frac{1}{N_{2}}=\frac{1}{N}+\frac{2}{N} \rho_{1}(1) \rho_{2}(1)
$$

where $N$ and $N_{2}$ are the initial and corrected numbers of degrees of freedom, respectively, and $\rho_{1}(1)$ and $\rho_{2}(1)$ are the 1 yr lag autocorrelations in the 2 variables considered, $\operatorname{var}_{1}$ and $\operatorname{var}_{2}$. The corrected number of degrees of freedom $N_{2}$ is then used in the statistical test of correlation between $\operatorname{var}_{1}$ and $\operatorname{var}_{2}$.

A random-effects meta-analysis (Hedges \& Olkin 1985) was used to test whether the 6 correlations (correlation of both $W_{\text {inf } y c, p o p}$ and $k_{y c, p o p}$ with $\operatorname{SST}_{y c, p o p,} \operatorname{densTSB}_{y c, p o p}$ and densRCT $\left.T_{y c, p o p}\right)$ were significant across all populations. For each correlation, the population level correlation coefficients $r_{p o p}$ were combined into weighted mean correlation coefficient $\bar{r}$ (Worm \& Myers 2003; see Appendix 1). The method also derives the confidence interval and the p-value associated with $\bar{r}$, which were used to decide whether a correlation was significant overall. In the fixed-effect analysis, the effects measured for herring in each population (here the $r_{p o p}$ ) are assumed to have the same value. The random effect meta-analysis allows variation of the effects (following a normal distribution) among populations. The latter method was pre- ferred here to allow for some variability between the populations in their response to temperature or density variations, which seems more realistic than an identical response.

\section{RESULTS}

\section{Temperature and herring biomass density}

Throughout the North Atlantic, herring live in very different temperature conditions and show strong differences in their biomass density (Fig. 2). The mean annual SST varies from 13.1 and $11.2^{\circ} \mathrm{C}$ for herring living at the southern border of the distribution (Celtic Sea and Gulf of Maine, respectively) to $6.2^{\circ} \mathrm{C}$ and $4.7^{\circ} \mathrm{C}$ on the northern border (Norwegian spring spawning herring and west of Newfoundland, respectively). The variation of the annual mean SST in each area during the period studied ranged from $0.72^{\circ} \mathrm{C}$ in Gulf of St. Lawrence to $1.65^{\circ} \mathrm{C}$ in the North Sea. Mean population biomass density varied between $0.23 \mathrm{t} \mathrm{km}^{-2}$ in the Irish Sea and $5.6 \mathrm{t} \mathrm{km}^{-2}$ for the Norwegian spring spawning population. The variation of population density for each population varied greatly: from $0.55 \mathrm{t} \mathrm{km}^{-2}$ in the Celtic Sea, to $12.1 \mathrm{t} \mathrm{km}^{-2}$ for the Norwegian spring spawning herring. A negative correlation $(r=$ $-0.61, p=0.027$ ) was found between the mean biomass density of a population and mean temperature.

\section{Growth at species level}

Substantial differences were found in mean growth curves among the 15 populations (Fig. 3 , Table 2); $w_{\text {inf }}$

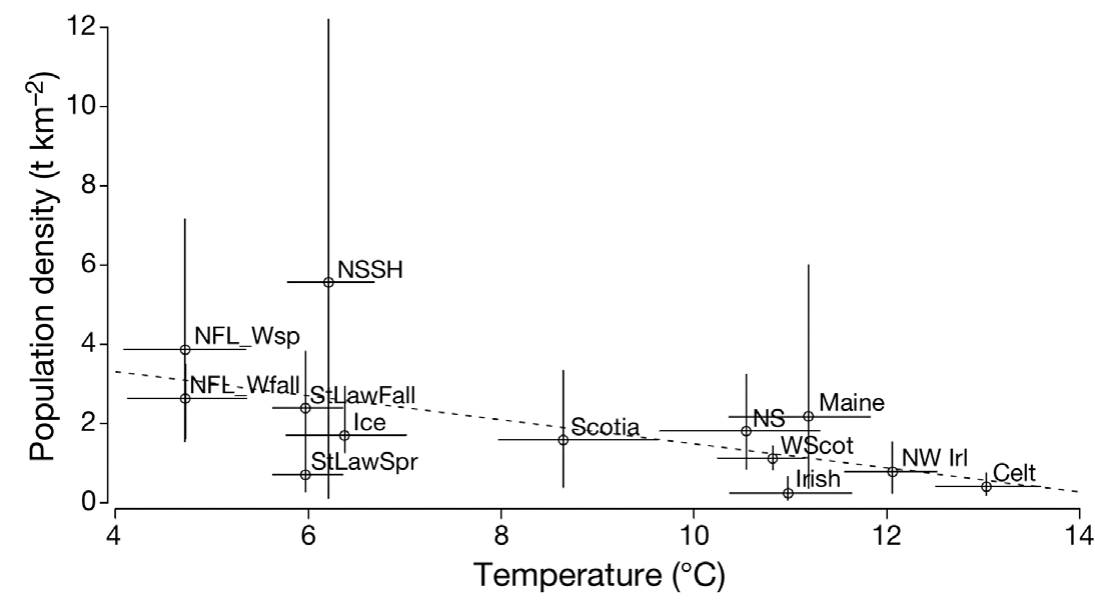

Fig. 2. Clupea harengus. Relationship between population density and temperature among North Atlantic Herring populations (see Table 1). Dots represent the interannual mean, and crosses represent the interannual variability (5th and 95th percentiles). Dashed line: linear regression of mean density vs. mean temperature $\left(\mathrm{R}^{2}=0.37, \mathrm{p}=0.027\right)$ 

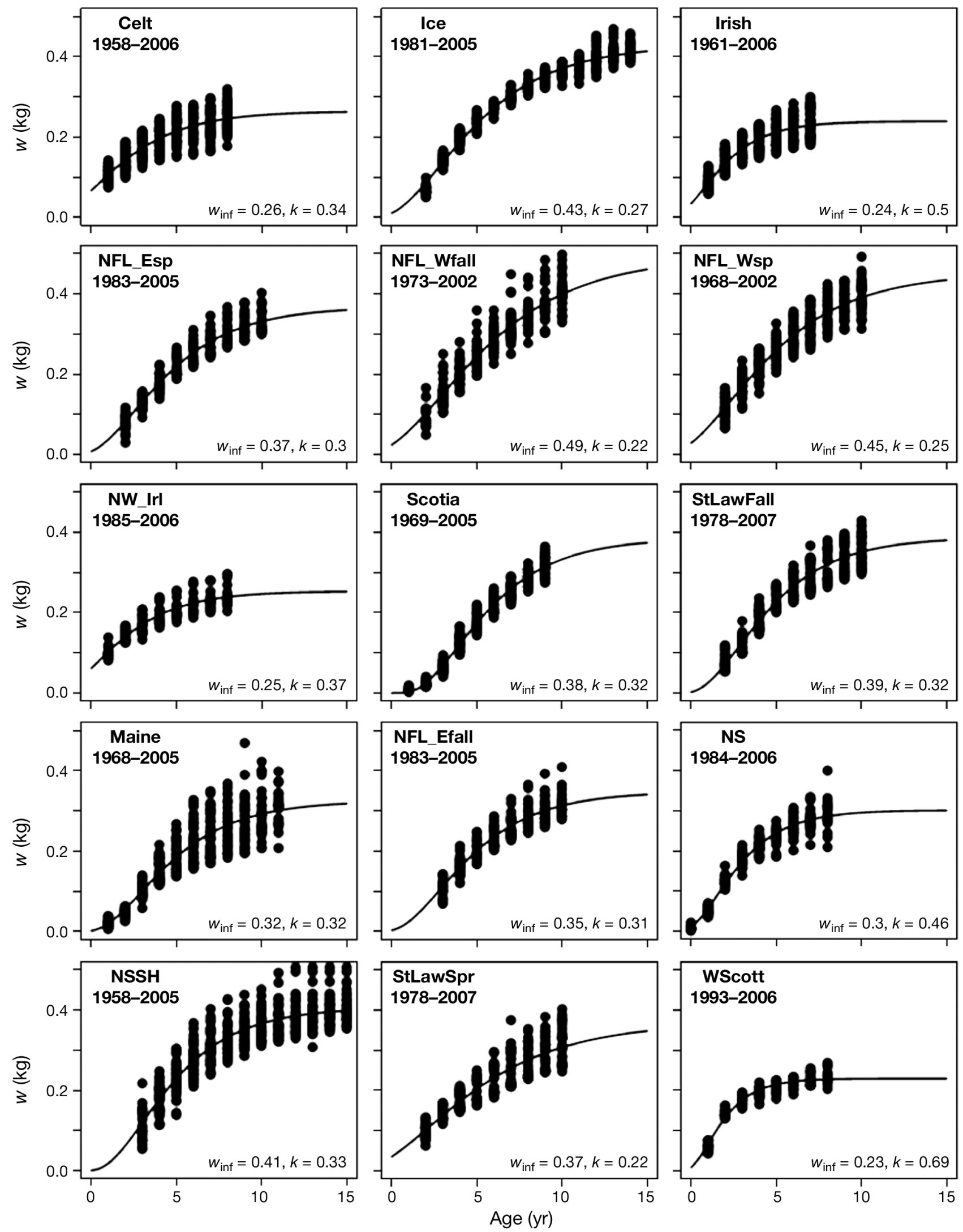

Fig. 3. Clupea harengus. Weight-at-age $(w)$ data, growth curves, and von Bertalanffy equation parameters for herring from 15 North Atlantic populations (see Table 1) 
Table 2. Results of the fit of von Bertalanffy equation on the weight-at-age data of herring from 15 populations (see Table 1)

\begin{tabular}{|lccccccc|}
\hline Population & $W_{\text {inf }}$ & $\mathrm{p}$ & $k$ & $\mathrm{p}$ & $t_{0}$ & $\mathrm{p}$ & $\mathrm{R}^{2}$ \\
\hline Celt & 0.26 & $<10^{-3}$ & 0.34 & $<10^{-3}$ & -2.94 & $<10^{-3}$ & 0.71 \\
Ice & 0.43 & $<10^{-3}$ & 0.27 & $<10^{-3}$ & -1.26 & $<10^{-3}$ & 0.97 \\
Irish & 0.24 & $<10^{-3}$ & 0.50 & $<10^{-3}$ & -1.48 & $<10^{-3}$ & 0.76 \\
Maine & 0.32 & $<10^{-3}$ & 0.32 & $<10^{-3}$ & -0.55 & $<0.03$ & 0.81 \\
NFL_Efall & 0.35 & $<10^{-3}$ & 0.31 & $<10^{-3}$ & -0.67 & $<0.10$ & 0.86 \\
NFL_Esp & 0.37 & $<10^{-3}$ & 0.30 & $<10^{-3}$ & -1.06 & $<10^{-3}$ & 0.91 \\
NFL_Wfall & 0.49 & $<10^{-3}$ & 0.22 & $<10^{-3}$ & -2.05 & $<10^{-3}$ & 0.86 \\
NFL_Wsp & 0.45 & $<10^{-3}$ & 0.25 & $<10^{-3}$ & -2.00 & $<10^{-3}$ & 0.88 \\
NS & 0.30 & $<10^{-3}$ & 0.46 & $<10^{-3}$ & -0.86 & $<10^{-3}$ & 0.95 \\
NSSH & 0.41 & $<10^{-3}$ & 0.33 & $<10^{-3}$ & -0.33 & $<0.17$ & 0.82 \\
NW Irl & 0.25 & $<10^{-3}$ & 0.37 & $<10^{-3}$ & -2.61 & $<10^{-3}$ & 0.82 \\
Scotia & 0.38 & $<10^{-3}$ & 0.32 & $<10^{-3}$ & 0.39 & $<10^{-3}$ & 0.97 \\
StLawFall & 0.39 & $<10^{-3}$ & 0.32 & $<10^{-3}$ & -0.59 & $<0.01$ & 0.90 \\
StLawSpr & 0.37 & $<10^{-3}$ & 0.22 & $<10^{-3}$ & -2.75 & $<10^{-3}$ & 0.80 \\
WScot & 0.23 & $<10^{-3}$ & 0.69 & $<10^{-3}$ & -0.58 & $<10^{-3}$ & 0.93 \\
\hline
\end{tabular}

ranged from $0.23 \mathrm{~kg}$ for the West of Scotland herring to $0.49 \mathrm{~kg}$ for West of Newfoundland (autumn spawners). The parameter $k$ ranged from $0.22 \mathrm{yr}^{-1}$ for Gulf of St. Lawrence spring spawning herring to $0.69 \mathrm{yr}^{-1}$ for West of Scotland herring.

Colder waters are correlated with a longer lifespan, higher asymptotic weight and lower growth coefficient in herring (Fig. 4). A significant positive correlation was found between mean population biomass density and $W_{\text {inf, }}$ while the correlation between mean population biomass density and $k$ was not significant. Correlations between mean recruits density and both $k$ and $W_{\text {inf }}$ were not significant (results not shown).

\section{Growth at population level}

The correlation between $W_{\text {inf }}$ yc,pop and $\mathrm{SST}_{y c, p o p}$ ranged from -0.90 (West of Scotland) to 0.40 (Nova Scotia / Bay of Fundy, Fig. 5). The correlation was significantly negative for herring from 3 of the 15 populations and significantly positive for none. The weighted mean correlation coefficient for the $w_{\text {inf }}-$ SST correlation indicated a significant negative relationship (Fig. 5, Table 3). For the parameter $k$, the correlation with SST ranged from -0.65 (St. Lawrence spring spawners) to 0.59 (North Sea) and was only significant for these 2 populations. The weighted mean correlation coefficient $\bar{r}$ for this relationship was negative and not significant.

A wide range of values was also observed for the correlations between $w_{\text {inf }}$ and biomass density (from -0.76 to 0.62 ). This correlation was significant and positive in 1 population (Irish Sea) and significant and negative in 2 populations. The weighted average correlation $\bar{r}$ was negative and not significantly different from zero (Table 3). Correlations between $k$ and biomass density
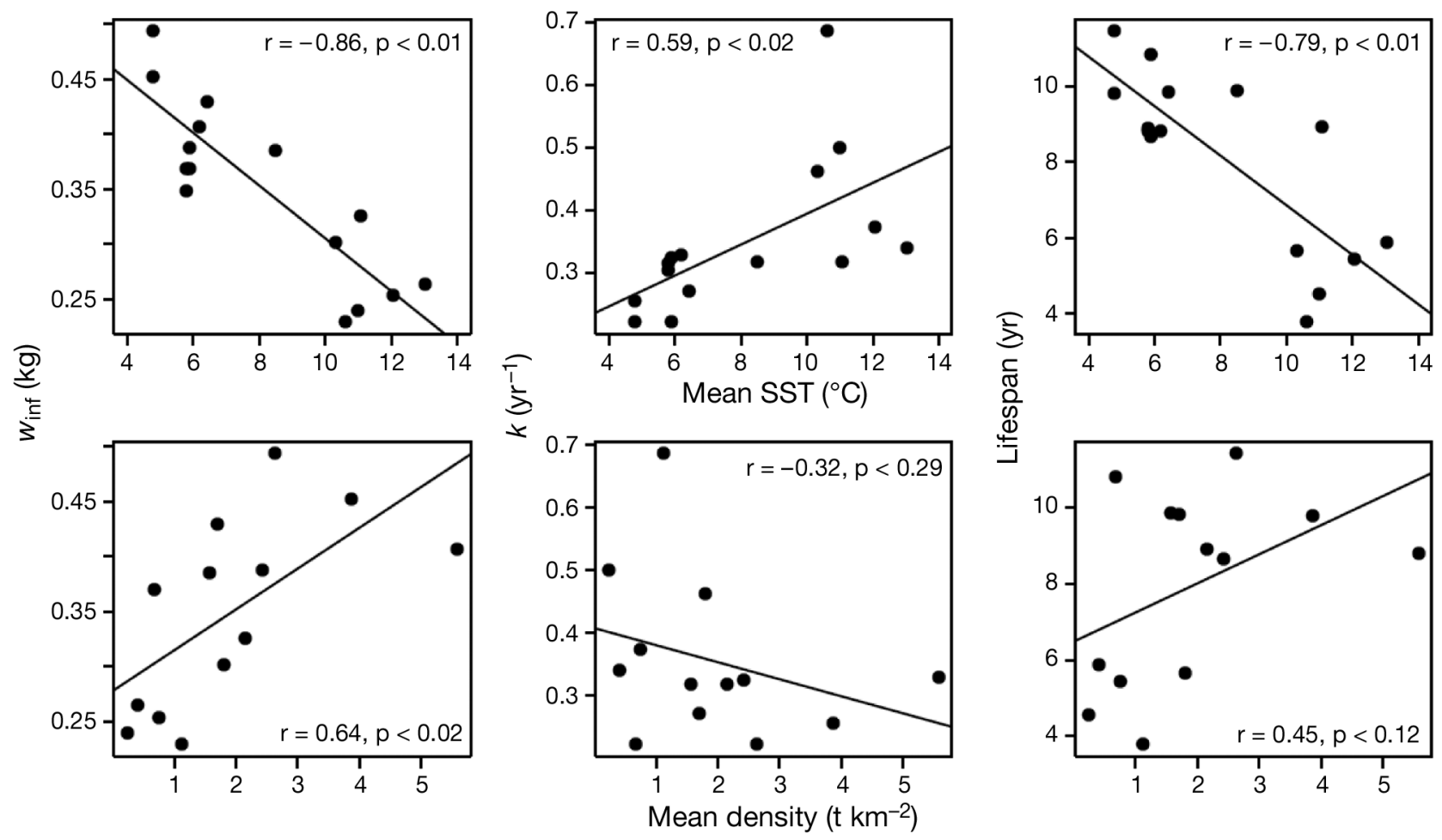

Fig. 4. Clupea harengus. Species level correlations of temperature (SST) and biomass density with herring growth (von Bertalanffy parameters $W_{\text {inf }}$ and $k$, and longevity $A_{95}$ ) 
Correlation $w_{\text {inf }}$ vs. SST

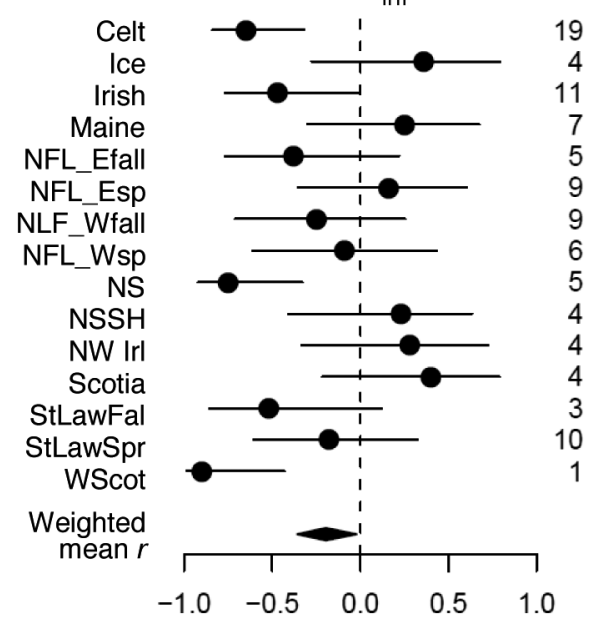

Correlation $w_{\text {inf }}$ vs. densTSB

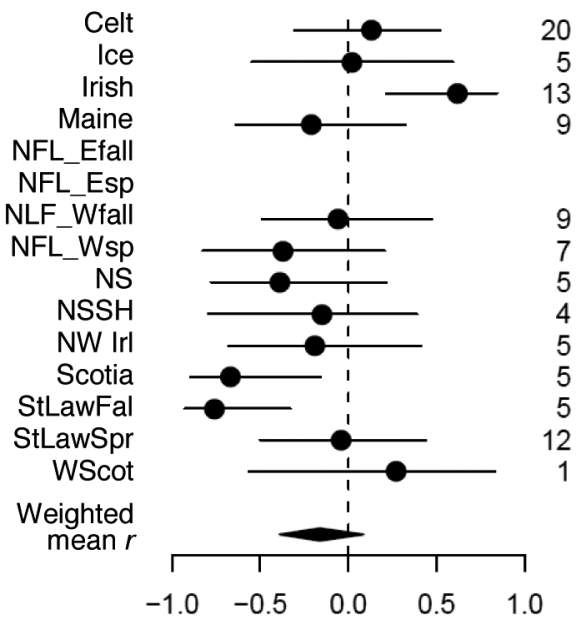

Correlation $w_{\text {inf }}$ vs. densRCT

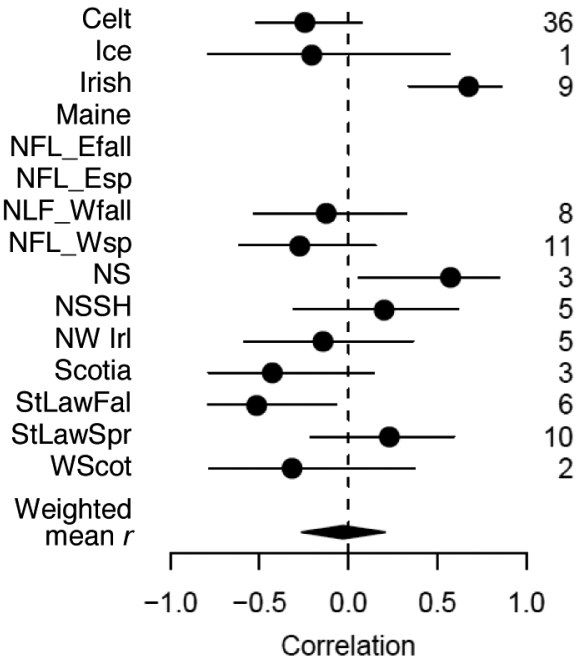

Correlation $k$ vs. SST

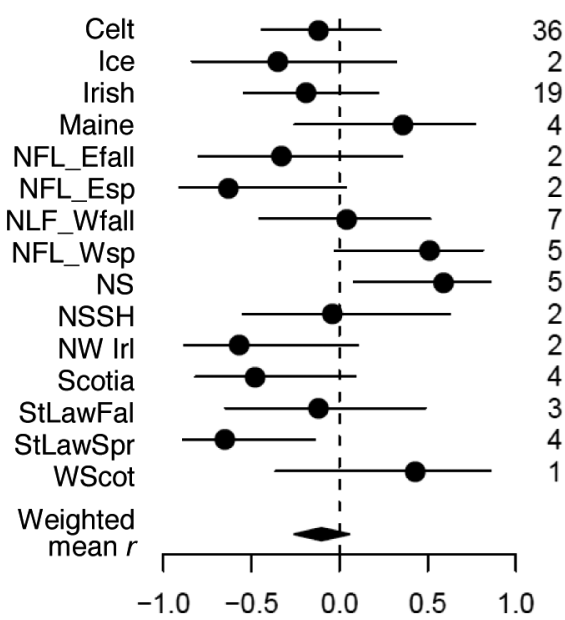

Correlation $k$ vs. densTSB

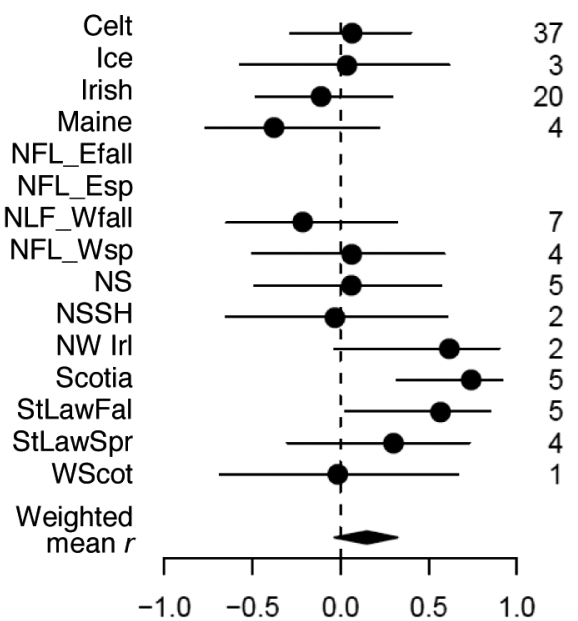

Correlation $k$ vs. densRCT

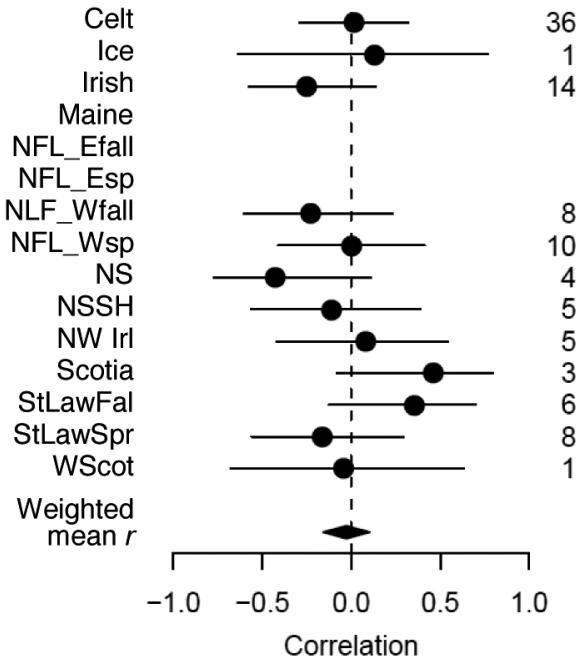

Fig. 5. Clupea harengus. Population-level correlations (with $95 \%$ confidence intervals) between von Bertalanffy parameters and SST, biomass density and recruit density for herring in each population (circles and bars; see Table 1), and the weighted mean correlation across all the populations with confidence interval (diamond). Relative weighting of populations are shown at right in each graph 
Table 3. Random effect meta-analysis reporting the weighted average correlation coefficients $\bar{r}$ for the 6 relationships tested between cohort-specific growth parameters and SST, densTSB and densRCT. N: no. of populations

\begin{tabular}{|lccc|}
\hline Correlations & $\mathrm{N}$ & $\bar{r}$ & $\mathrm{p}$ \\
\hline$W_{\text {inf }}-\mathrm{SST}$ & 15 & -0.196 & 0.036 \\
$k-\mathrm{SST}$ & 15 & -0.102 & 0.136 \\
$W_{\text {inf }}-$ densTSB & 13 & -0.161 & 0.176 \\
$k-$ densTSB & 13 & 0.150 & 0.112 \\
$W_{\text {inf }}-$ densRCT & 13 & -0.029 & 0.388 \\
$k-$ densRCT & 13 & -0.027 & 0.368 \\
\hline
\end{tabular}

varied from -0.37 for the Gulf of Maine / Georges Bank herring to 0.74 in the Nova Scotia / Bay of Fundy herring and were significantly positive for 2 populations. The combined correlation $\bar{r}$ revealed a positive, but non-significant relationship.

The population level correlations between $w_{\text {inf }}$ and densRCT were significant and positive for the Irish Sea and North Sea populations and negative for the St. Lawrence population (autumn spawner). The correlation for $k$ and densRCT was significant for none of the populations. The weighted average correlations for the effect of densRCT on $k$ and $w_{\text {inf }}$ were both close to zero and non-significant.

\section{DISCUSSION}

The effects of temperature and population density on Atlantic herring growth were investigated at the population level, with contrasting results among populations. Looking at these effects at the species scale, we find that temperature plays a major role in herring growth. As is the case for Atlantic cod (Taylor 1958), individual herring living in low temperature areas tend to have a larger asymptotic size and to grow slower towards this asymptotic size than individuals living in warmer waters.

The pattern of growing to bigger maximum size for individuals living in a cold environment than for individuals of the same species living in a warmer environment is commonly found among ectotherms (Ray 1960, Atkinson 1994) and is referred to as 'Bergmann's rule' (see e.g. Blackburn et al. 1999). Genetic adaptation of populations to the local temperature could explain this rule (Atkinson \& Sibly 1997). Being bigger at low temperature constitutes an advantage in endotherms, as it results in a lower ratio of body surface to body mass, thus reducing heat loss. But it remains unclear how this applies to ectotherms. Besides, larger body size at lower temperature is also observed with animals from a same population reared at different temperatures; this is consistent with a developmental response to temperature as a result of phenotypic plasticity (Atkinson \& Sibly 1997). Aquaculture studies show that the relationship between growth rate and temperature is dome-shaped, e.g. in cod Gadus morhua (Pedersen \& Jobling 1989, Björnsson et al. 2001), turbot Scophthalmus maximus (Burel et al. 1996), Atlantic halibut Hippoglossus hippoglossus (Jonassen et al. 1999) and spotted wolfish Anarhichas minor (Imsland et al. 2006). The optimum temperature (at which maximum growth rate is observed) and maximum growth rate both decrease while the size increases during fish life (Jonassen et al. 1999, Björnsson et al. 2001, Imsland et al. 2006). According to this temperature-size-growth relationship, fish living at a higher temperature have a higher growth rate than fish at a lower temperature when they are young, because optimum temperature for growth is high for the smaller fish. Later on in life, as optimum temperature becomes lower, fish living at cooler temperature have a higher growth rate than fish living at higher temperature.

Factors such as phenology also change with latitude, i.e. the length of the growing season tends to be shorter at high latitudes (Schwartz 2003); this may contribute to the pattern of lower $k_{\text {pop }}$ at low temperature observed here for herring.

The relationships with temperature found at the species level are only partially observed in herring within a population. The correlation between inter-cohort differences in growth in herring within a population and mean temperature experienced by the cohorts was significant for $w_{\text {inf } y c, p o p}$ but not for $k_{y c, p o p}$. At the population level, the range of variation in mean temperature experienced by a cohort is probably too small for the effect of temperature to be significant $\left(1^{\circ} \mathrm{C}\right.$ on average within a population vs. $8.3^{\circ} \mathrm{C}$ among populations). The population with the widest range of variation in annual mean temperature $\left(1.65^{\circ} \mathrm{C}\right)$, North Sea herring, is the only population to have a significant positive correlation between $k_{y c, p o p}$ and $\mathrm{SST}_{y c, p o p}$ and a significant negative correlation between $W_{\text {inf } y c, p o p}$ and $\mathrm{SST}_{y c, p o p}$ (Fig. 5).

There may be other factors that combine with the effect of temperature to influence growth at the cohort level. Variations in prey abundance also affect herring growth (Glover 1957, Burd 1984). In the Baltic Sea, climate-induced changes in the abundance of mesozooplankton caused a drastic decrease in Baltic herring growth (reduction of $w_{\text {inf }}$ by one-half) during the 1980s (Rönkkönen et al. 2004, Möllmann et al. 2005). Heath et al. (1997) found that variability in zooplankton abundance could explain the interannual variations in the growth of juvenile North Sea herring. Shin \& Rochet (1998) showed that asymptotic length in the same population was positively correlated to the production of prey. However in the present study, the effect of tem- 
perature on North Sea herring growth was significant although plankton abundance was not taken into account, which suggests either that the effect of temperature is more determining, or that the variations in plankton abundance may be to some extent linked to temperature variations.

The weight-at-age data used here to study herring growth might be affected by various sources of error, which could to some extent explain the lack of relationship between cohort-specific growth parameters and SST. Old individuals are generally underrepresented in the catches and therefore inadequately sampled, and are often inaccurately aged, resulting in a poor precision of the estimates of weight-at-age (Molloy 1984), which could reflect on the accuracy of the cohort estimates of growth parameters. Additionally, 'Lee's phenomenon' (Ricker 1969) may affect the quality of the data; in a heavily fished population, the fast growing individuals are removed earlier than the slow growing ones, due to size-selective fishing mortality. The weight-at-age for the older ages is thus only representative of the slow growers, which results in a bias on the estimates of VB parameters compared to the same population at lower fishing mortality. For stocks that have experienced large changes in the fishing mortality, this effect might interfere with the present analysis, since it may be responsible for spurious temporal variations in growth parameters (Walker et al. 1998).

The quality of the data may also be affected by the different temporal resolution for the weight-at-age data for the different stocks. Growth parameters, especially at the cohort level, might be less accurately estimated for stocks that have fewer ageclasses represented in the data (e.g. Irish Sea, 7 ageclasses) than for stocks with more age-classes (e.g 13 for Icelandic herring). This might hamper our analysis and partly explain the lack of relationship observed. However, it seems reasonable to assume that for the majority of the stocks, most of the growth curve is covered by the data, and that the growth parameters estimates are not strongly biased. Indeed, the lack of weight data for old ages in some stocks (e.g. Irish and Celtic Seas, West of Scotland) is probably not related to a lack of sampling for older ages but due to their shorter lifespan and the lack of old individuals in those populations.

Finally, variations in weight may not only reflect variations in growth, but also in fish condition. Lengthat-age data, which would have been more appropriate for this study, are rarely published or reported in stock assessment reports. In the case of the clupeids, body condition is principally affected by prey abundance (Casini et al. 2006, Flinkman et al. 1998), and on the variations in competitor clupeid species (interspecies density dependent mechanism; Casini et al. 2006). Temperature may affect condition via a control on the abundance of food (bottom-up effect), but may also have a direct physiological effect (Cui \& Wootton 1988). However, no evidence of temporal correlation between condition variations and temperature has been found in herring populations (Engelhard \& Heino 2006, Óskarsson 2008).

The VB equation was originally derived from an energetic theory of growth (von Bertalanffy 1957), in which the $k$ parameter is proportional to the rate of energy consumption for body maintenance and $w_{\text {inf }}$ is the cube of the ratio between the rate of energy intake and the maintenance rate (see e.g. Ricklefs 2003). Density dependence affects growth through the increased competition for food at high population abundance, and should have a negative effect on the rate of energy intake per individual, while it should not affect the rate of energy consumption for maintenance. Consequently, a lower asymptotic weight should be expected when density dependence is strong, but $k$ should not be affected by density dependence. This pattern has been observed for asymptotic weight in a number of fish (Beverton \& Holt 1957, Lorenzen 1996, Morimoto 2003, Vincenzi et al. 2007) and mammals (Etnier 2004, Laidre et al. 2006, Liu et al. 2008). These studies however differed about the effect on $k$, some finding a strong positive effect of density dependence (Liu 2008) and others finding a negative effect (Morimoto 2003, Laidre et al. 2006), or no effect at all (Vincenzi et al. 2007).

At the population level, the meta-analysis indicated that biomass and recruit density did not have a significant effect on cohort-specific growth parameters. Some populations showed the expected significant negative correlation between densTSB and $w_{\text {inf }}$ (Nova Scotia and Bay of Fundy, St. Lawrence, fall spawners), but others showed a positive correlation (Irish Sea). Investigating the variability in population density (as biomass or recruitment) as a proxy for the strength of density dependence assumes that the carrying capacity of the ecosystem for that population does not change in time. This is however not likely to happen in nature, where the carrying capacity of an ecosystem for a population fluctuates in response to the variable environment (Barbault 1981). Ideally, the intensity of density dependence should be measured by the ratio between the annual values of population size and carrying capacity. Some stock-assessment methods, such as biomass dynamics models (see e.g. Hilborn \& Walters 1992) can provide estimates of the carrying capacity of a stock within a system. These models, however, require time series of the total catch and an abundance index, which were not available for all the herring stocks studied here. Besides, these 
methods also make the assumption of a constant carrying capacity. Changes in population size in many herring stocks in the last $40 \mathrm{yr}$ have been caused by the interaction of fishing and changes in ecosystem carrying capacity (Toresen \& Ostvedt 2000, Simmonds 2007, Payne et al. 2009). It is difficult to distinguish or resolve the relative influences of these two factors. However it is the impact of fishing that has caused the biggest change in biomass through the collapse of stocks through recruitment overfishing. Therefore, our approach was to acknowledge the impact of variability in carrying capacity, but assume that the variations in stock biomass probably provide a good indicator of the variations in the strength of density dependence. A number of studies have found a density-dependent reduction in herring growth using TSB or RCT, which suggest that these two metrics are acceptable proxies for density dependence (Moores \& Winters 1982, Burd 1984, Husebø et al. 2007, Melvin \& Stephenson 2007). These studies however analyzed the variations in weight-at-age or annual growth rate during the first years of life, and it is not clear how their findings could be interpreted in term of VB equation parameters.

At the species level, using average population density to look at differences in the intensity of density dependence amongst populations is based on the assumption that the carrying capacity (expressed in density) is the same in all ecosystems and that the difference in observed densities is the consequence of the populations being exposed to different levels of fishing pressure. However the negative correlation observed between herring population density and the average temperature (Fig. 2) suggests that differences in population density actually reflect differences in carrying capacity for herring in the different ecosystems. Species living at high latitude tend to have higher population densities that species living at lower latitudes (Gaston \& Blackburn 1996, Symonds et al. 2006). This pattern may be due to the decrease of species diversity at higher latitudes (i.e. lower temperatures), which may result in lower competition among species at the same trophic level. This pattern has however not been studied at the species scale, comparing local population density with population latitude. The species level analysis of the effect of density dependence on herring growth only provided indication of a positive relationship between $w_{\text {inf }}$ and densTSB, which is the opposite of the theoretical expectation. This correlation might result from the inverse relationship between average temperature and both asymptotic weight and population density.

In the context of global warming, it is important to know the functional relationship between temperature and growth, in order to be able to model the likely con- sequences of temperature increase on the dynamics of the productivity in a population. The present study provides evidence for an effect of temperature on herring growth at the scale of the species, but provides only limited evidence that this relationship also applies at the population level, probably because of the limited range of temperature variation observed for some populations. According to multi-model results published by the IPCC (2001), cited by Drinkwater (2005), a temperature increase of between 2 and $6^{\circ} \mathrm{C}$ is expected in the North Atlantic during the present century. This range of variation is substantially higher than the one observed so far for each herring population (between 0.72 and $1.65^{\circ} \mathrm{C}$ of amplitude among areas) and it is therefore likely that the growth-temperature relationship will be observed within populations. Individual growth in fish, as described by weight or growth increment at age, is supposed to be positively related to temperature (see Moores \& Winters 1982, Anthony \& Fogarty 1985, Husebø et al. 2007 for herring; Brander 1995 for cod; Thresher et al. 2007 for 7 South Pacific species). This might lead one to assume that future water warming will enhance the growth of individuals in fish populations. However, these studies focused on the youngest age classes and did not investigate growth of the older ages. The temperature-growth relationship presented here implies that a temperature increase would indeed lead to higher body weight for young ages, but to smaller body weight for older fish and shorter life expectancy. However, this direct effect of temperature may be tempered by the effect of other changes triggered by global warming, such as changes in food availability, population density and recruitment.

Acknowledgements. The authors thank C. LeBlanc (DFO Canada), B. Overholtz (National Marine Fisheries Service, USA), M. Power (St. Andrews Biological Station, Canada) and J. P. Wheeler (DFO Canada) for providing the data for the Gulf of St. Lawrence, the Gulf of Maine/Georges Bank, the Nova Scotia/Bay of Fundy and the East of Newfoundland stocks respectively. Also, the ICES working groups are thanked for collating the time series of herring in Europe. Part of this study was supported by the EU 6th Framework projects UNCOVER and RECLAIM.

\section{LITERATURE CITED}

Anthony VC, Fogarty MJ (1985) Environmental effects on recruitment, growth, and vulnerability of Atlantic herring (Clupea harengus harengus) in the Gulf of Maine region. Can J Fish Aquat Sci 42:158-173

> Atkinson D (1994) Temperature and organism size-a biological law for ectotherms? Adv Ecol Res 25:1-58

Atkinson D, Sibly RM (1997) Why are organisms usually bigger in colder environments? Making sense of a life history puzzle. Trends Ecol Evol 12:235-239 
Barbault R (1981) Ecologie des populations et des communautés. Masson, Paris

Bekkevold D, André C, Dahlgren TG, Clausen LAW and others (2005) Environmental correlates of population differentiation in Atlantic herring. Evolution 59:2656-2668

Beverton RJH, Holt SJ (1957) On the dynamics of exploited fish populations. Fish Inv Lond (Ser 2) 19:1-533

Björnsson B, Steinarsson A, Oddgeirsson M (2001) Optimal temperature for growth and feed conversion of immature cod (Gadus morhua L.). ICES J Mar Sci 58:29-38

Blackburn TM, Gaston KJ, Loder N (1999) Geographic gradients in body size: a clarification of Bergmann's rule. Divers Distrib 4:165-174

Brander KM (1995) The effect of temperature on growth of Atlantic cod (Gadus morhua L.). ICES J Mar Sci 52:1-10

Brander KM (2007) The role of growth changes in the decline and recovery of North Atlantic cod stocks since 1970. ICES J Mar Sci 64:211-217

Brett JR (1979) Environmental factors and growth. In: Hoar WS, Randall DJ, Brett JR (eds) Fish physiology, Vol 8. Academic Press, New York, p 599-675

Brunel T, Boucher J (2006) Pattern of recruitment variability in the geographical range of the exploited northeast Atlantic fish species. J Sea Res 55:156-168

Burd AC (1984) Density dependent growth in North Sea herring. ICES CM 1984/H:4

Burel C, Person-Le Ruyet J, Gaumet F, Le Roux A, Sévère A, Boeuf G (1996) Effects of temperature on growth and metabolism in juvenile turbot. J Fish Biol 49:678-692

Casini M, Cardinale M, Hjelm J (2006) Inter-annual variation in herring, Clupea harengus, and sprat, Sprattus sprattus, condition in the central Baltic Sea: What gives the tune? Oikos 112:638-650

Clark RA, Fox CJ, Viner D, Livermore M (2003) North Sea cod and climate change - modelling the effects of temperature on population dynamics. Glob Change Biol 9:1669-1680

> Cui Y, Wootton RJ (1988) Effects of ration, temperature and body size on the body composition, energy content and condition of the minnow, Phoxinus phoxinus (L.). J Fish Biol 32:749-764

> Dickey-Collas M, Clarke M, Slotte A (2009) 'Linking herring': Do we really understand plasticity? ICES J Mar Sci 66: 1649-1651

- Drinkwater KF (2005) The response of Atlantic cod (Gadus morhua) to future climate change. ICES J Mar Sci 62: 1327-1337

Engelhard GH, Heino M (2004) Maturity changes in Norwegian spring-spawning herring Clupea harengus: compensatory or evolutionary responses? Mar Ecol Prog Ser 272: 245-256

Engelhard GH, Heino M (2006) Climate change and condition of herring (Clupea harengus) explain long-term trends in extent of skipped reproduction. Oecologia 149:593-603

Etnier M (2004) Reevaluating evidence of density-dependent growth in northern fur seals (Callorhinus ursinus) based on measurements of archived skeletal specimens. Can J Fish Aquat Sci 61:1616-1626

FAO (2007) The state of world fisheries and aquaculture in 2006. FAO, Rome

Flinkman J, Aro E, Vuorinen I, Viitasalo M (1998) Changes in northern Baltic zooplankton and herring nutrition from 1980s to 1990s: top-down and bottom-up processes at work. Mar Ecol Prog Ser 165:127-136

- Gaston KJ, Blackburn TM (1996) Global scale macroecology: interactions between population size, geographic range size and body size in the Anseriformes. J Anim Ecol 65: $701-714$
Geffen AJ (2009) Advances in herring biology: from simple to complex, coping with plasticity and adaptability. ICES J Mar Sci 66:1688-1695

Glover RS (1957) The environment: the evidence of the plankton. Rapp PV Reun Cons Int Explor Mer 143:22-24

Grégoire F, Lefebvre L, Lavers J (2004) Analytical assessment and risk analysis for the spring spawning herring (Clupea harengus harengus L.) stock of the west coast of Newfoundland (NAFO division 4R) in 2003. DFO Can Sci Advis Sec Res Doc 2004/090

> Hay DE, Rose KA, Schweigert J, Megrey BA (2008) Geographic variation in North Pacific herring populations: pan-Pacific comparisons and implications for climate change impacts. Prog Oceanogr 77:233-240

Heath M, Scott B, Bryant AD (1997) Modelling the growth of herring from four different stocks in the North Sea. J Sea Res 38:413-436

Hedges LV, Olkin I (1985) Statistical methods for meta-analysis. Academic Press, San Diego, CA

Heincke FBO (1898) Naturgeschichte des Herings I. Die Lokalformen und die Wanderungen des Herings in den europaischen Meeren. SalleAbhandlungen der deutschen Seefischereivereins, Vol 2

Hilborn R, Walters CJ (1992) Quantitative fisheries stock assessment. Choice, dynamics and uncertainty. Chapman \& Hall, London

Houde ED (1989) Comparative growth, mortality, and energetics of marine fish larvae: temperature and implied latitudinal effects. Fish Bull 87:471-495

Husebø A, Slotte A, Stenevik EK (2007) Growth of juvenile Norwegian spring-spawning herring in relation to latitudinal and interannual differences in temperature and fish density in their coastal and fjord nursery areas. ICES J Mar Sci 64:1161-1172

ICES (2007a) Report of the Herring Assessment Working Group for the area south of $62^{\circ} \mathrm{N}$. ICES CM 2007/ ACFM:11

ICES (2007b) Report of the North-Western Working Group. ICES CM 2007/ACFM:17

ICES (2007c) Report of the Northern Pelagic and Blue Whiting Fisheries Working Group. ICES CM 2007/ACFM:29

Imsland AK, Foss A, Sparboe LO, Sigurdsson S (2006) The effect of temperature and fish size on growth and feed efficiency ratio of juvenile spotted wolffish Anarhichas minor. J Fish Biol 68:1107-1122

IPCC (2001) Climate change 2001: the scientific basis. Cambridge University Press, Cambridge

Jonassen TM, Imsland AK, Stefansson SO (1999) The interaction of temperature and fish size on growth of juvenile halibut. J Fish Biol 54:556-572

Laidre KL, Estes JA, Tinker MT, Bodkin J, Monson D, Schneider K (2006) Patterns of growth and body condition in sea otters from the Aleutian Archipelago before and after the recent population decline. J Anim Ecol 75:978-989

LeBlanc $\mathrm{CH}$, Poirier GA, MacDougall C, Bourque C, Roy J (2007) Assessment of the NAFO 4T southern Gulf of St. Lawrence herring stocks in 2006. DFO Can Sci Advis Sec Res Doc 2007/016

Liu KM, Cheng YT, Chen WK, Chen CT, Su WC (2008) Examining the density-dependent effect on the growth of dolphinfish, Corphaena hippurus in the eastern Taiwan waters. J Fish Soc Taiwan 35:101-115

> Lorenzen K (1996) A simple von Bertalanffy model for density-dependent growth in extensive aquaculture, with an application to common carp (Cyprinus carpio). Aquaculture 142:191-205

Melvin GD, Stephenson RL (2007) The dynamics of a recovering 
fish stock: Georges Bank herring. ICES J Mar Sci 64:69-82

Möllmann C, Kornilovs G, Fetter M, Koster FW (2005) Climate, zooplankton, and pelagic fish growth in the central Baltic Sea. ICES J Mar Sci 62:1270-1280

Molloy J (1984) Density dependent growth in Celtic Sea herring. ICES CM 1984/H:30

Moores JA, Winters GH (1982) Growth patterns in a Newfoundland Atlantic herring (Clupea harengus harengus) stock. Can J Fish Aquat Sci 39:454-461

Morimoto H (2003) Age and growth of Japanese sardine Sardinops melanostictus in Tosa Bay, south-western Japan during a period of declining stock size. Fish Sci 69: 745-754

- Myers RA, MacKenzie BR, Bowen KG, Barrowman NJ (2001) What is the carrying capacity for fish in the ocean? A meta-analysis of population dynamics of North Atlantic cod. Can J Fish Aquat Sci 58:1464-1476

Óskarsson GJ (2008) Variation in body condition, fat content and growth rate of Icelandic summer-spawning herring Clupea harengus L. J Fish Biol 72:2655-2676

Overholtz WJ, Jacobson LD, Melvin GD, Cieri M, Power M, Libby D, Clark K (2004) Stock assessment of the Gulf of Maine-Georges Bank Atlantic herring complex, 2003. Northeast Fish Sci Cent Ref Doc 04-06

> Payne MR, Hatfield EMC, Dickey-Collas M, Falkenhaug T and others (2009) Recruitment in a changing environment: the 2000s North Sea herring recruitment failure. ICES J Mar Sci 66:272-277

> Pedersen T, Jobling M (1989) Growth rates of large, sexually mature cod Gadus morhua, in relation to condition and temperature during an annual cycle. Aquaculture 81:161-168

Planque B, Fredou T (1999) Temperature and the recruitment of Atlantic cod (Gadus morhua). Can J Fish Aquat Sci 56: 2069-2077

Power MJ, Clark KJ, Fife FJ, Knox D, Melvin GD, Stephenson RL, Annis LM (2006) 2006 Evaluation of 4VWX Herring. DFO Can Sci Advis Sec Res Doc 2006/49

Pyper BJ, Peterman RM (1998) Comparison of methods to account for autocorrelation in correlation analyses of fish data. Can J Fish Aquat Sci 55:2127-2140

R Development Core Team (2006) R: a language and environment for statistical computing. R Foundation for Statistical Computing, Vienna

Ray C (1960) The application of Bergmann's and Allen's rules to the poikilotherms. J Morphol 106:85-108

Ricker WE (1969) Effects of size-selective mortality and sampling bias on estimates of growth, mortality, production, and yield. J Fish Res Bd Can 26:479-541

Ricklefs RE (2003) Is rate of ontogenetic growth constrained by resource supply or tissue growth potential? A comment on West et al.'s model. Funct Ecol 17:384-393

Rönkkönen S, Ojaveer E, Raid T, Viitasalo M (2004) Longterm changes in Baltic herring (Clupea harengus mem- bras) growth in the Gulf of Finland. Can J Fish Aquat Sci 61:219-229

Ruzzante DE, Mariani S, Bekkevold D, André C and others (2006) Biocomplexity in a highly migratory pelagic marine fish, Atlantic herring. Proc Biol Sci 273:1459-1464

Saville A, Bailey RS, Black M (1984) Variations in growth of herring in the Shetland area and to the west of Scotland in relation to population abundance. ICES CM 1984/H:61

Schwartz MD (2003) Phenology: an integrative environmental science. Springer, Berlin

Shin YJ, Rochet MJ (1998) A model for the phenotypic plasticity of North Sea herring growth in relation to trophic conditions. Aquat Living Resour 11:315-324

Simmonds EJ (2007) Comparison of two periods of North Sea herring stock management: success, failure, and monetary value. ICES J Mar Sci 64:686-692

Sinclair M, Solemdal P (1988) The development of "population thinking" in fisheries biology between 1878 and 1930. Aquat Living Resour 1:189-213

> Sinclair M, Sinclair A, Iles TD (1982) Growth and maturation of Southwest Nova Scotia Atlantic herring (Clupea harengus harengus). Can J Fish Aquat Sci 39:288-295

Symonds MRE, Christidis L, Johnson CN (2006) Latitudinal gradients in abundance, and the causes of rarity in the tropics: a test using Australian honeyeaters (Aves: Meliphagidae). Oecologia 149:406-417

Taylor CC (1958) Cod growth and temperature. J Cons Int Explor Mer 23:366-370

Thresher RE, Koslow JA, Morison AK, Smith DC (2007) Depth-mediated reversal of the effects of climate change on long-term growth rates of exploited marine fish. Proc Natl Acad Sci USA 104:7461-7465

Toresen R, Ostvedt OJ (2000) Variation in abundance of Norwegian spring-spawning herring (Clupea harengus, Clupeidae) throughout the 20th century and the influence of climatic fluctuations. Fish Fish 1:231-256

- Vincenzi S, Crivelli AJ, Jesensek D, Rubin JF, De Leo GA (2007) Density-dependent individual growth of marble trout (Salmo marmoratus) in the Soca and Idrijca river basins, Slovenia. Hydrobiologia 583:57-68

> von Bertalanffy L (1957) Quantitative laws in metabolism and growth. Q Rev Biol 32:217-231

> Walker TI, Taylor BL, Hudson RJ, Cottier JP (1998) The phenomenon of apparent change of growth rate in gummy shark (Mustelus antarcticus) harvested off southern Australia. Fish Res 39:139-163

Wheeler JP, Squires B, Williams P (2004) Newfoundland east and southeast coast herring - an assessment of the stocks to the spring of 2004. DFO Can Sci Advis Sec Res Doc 2004/101

Worm B, Myers RA (2003) Meta-analysis of cod-shrimp interactions reveals top-down control in oceanic food webs. Ecology 84:162-173 
Appendix 1. Random effect meta-analysis

This method was used to combine the population level correlation coefficients $r_{p o p}$ in a weighted mean correlation coefficient $\bar{r}$ to test whether the correlation tested for the $K$ populations is significant across all populations. We used the method described in Worm \& Myers (2003):

Let $r_{p o p}$ be the correlation coefficient between one cohort specific growth parameter in a given population pop (e.g. $\left.W_{\text {inf } y c, p o p}\right)$ and one explanatory variable (e.g. $\left.\mathrm{SST}_{y c, p o p}\right)$, and $N_{2 p o p}$ the corresponding number of degrees of freedom corrected to account for autocorrelations in both $w_{\text {inf } y c, p o p}$ and $\mathrm{SST}_{\text {yc,pop }}$.

The 'effect size' $d_{p o p}$ in the population pop (i.e. the magnitude of the effect of the explanatory variable on the growth parameter) is defined as the Fisher's $Z$ transform of $r_{p o p}$ :

$$
d_{\text {pop }}=0.5\left[\ln \left(\frac{1+r_{\text {pop }}}{1-r_{p o p}}\right)\right]
$$

and its variance is

$$
v_{p o p}=\frac{1}{N_{2 p o p}^{2}-1}+\frac{4-r_{p o p}^{2}}{2\left(N_{2 p o p}-1\right)^{2}}
$$

In fixed-effect meta-analysis, the effect size is assumed to be equal for all populations. Under this assumption the weighted mean effect size is:

$$
\bar{d}=\frac{\sum_{p o p=1}^{K} p_{p o p} d_{p o p}}{\sum_{p o p=1}^{K} p_{p o p}}
$$

where $K$ is the number of populations in the analysis (i.e. 15 for the test of the effects of SST and 13 for the effect of densTSB), and $p_{\text {pop }}$ represents the weight given to the population $p o p$, which is defined as $p_{p o p}=1 / v_{p o p}$. The variance $v$ associated to $\bar{d}$ is equal to:

$$
v=\frac{1}{\sum_{p o p=1}^{K} 1 / v_{p o p}}
$$

The weighted mean correlation coefficient is then obtained by applying the inverse of the $Z$ transform:

$$
\bar{r}=\left(\mathrm{e}^{2 \bar{d}}-1\right)\left(\mathrm{e}^{2 \bar{d}}+1\right)
$$

The $95 \%$ confidence interval for $\bar{r}$ is calculated by adding and subtracting $1.96 \sqrt{v}$ to $\bar{d}$ and applying the inverse of the $Z$ transform to the resulting values:

$$
\begin{aligned}
& \bar{r}_{\text {inf }}=\left[\mathrm{e}^{2(\bar{d}-1.96 \sqrt{v})}-1\right]\left[\mathrm{e}^{2(\bar{d}-1.96 \sqrt{v})}+1\right] \\
& \bar{r}_{\text {sup }}=\left[\mathrm{e}^{2(\bar{d}+1.96 \sqrt{v})}-1\right]\left[\mathrm{e}^{2(\bar{d}+1.96 \sqrt{v})}+1\right]
\end{aligned}
$$

The null hypothesis is rejected if the confidence interval does not contain zero. The null hypothesis can also be tested using the $Z$ statistics

$$
Z=\frac{|\bar{d}|}{\sqrt{v}}
$$

If $Z>1.96$, the null hypothesis can be rejected.

The assumption that effect size is equal for all populations (i.e. that all $d_{p o p}$ should be equal to $\bar{d}$ ) can be tested using the $Q$ statistic measuring the heterogeneity in the effect sizes $\left(d_{p o p}\right)$ :

$$
Q=\sum_{p o p=1}^{K} p_{p o p} d_{p o p}^{2}-\frac{\left(\sum_{p o p=1}^{K} p_{p o p} d_{p o p}\right)^{2}}{\sum_{p o p=1}^{K} p_{p o p}}
$$

In the case of the 6 correlations tested in the present study, the values observed for $Q$ were high (ranging from 70.9 to 142.3); this indicates that the hypothesis of homogenous effects is unlikely. The heterogeneity $Q$ should therefore be integrated in the test, using the random-effects meta-analysis model. Under this model, the variance of the effect size $d_{p o p}$ becomes

$$
v_{p o p}^{\prime}=v_{p o p}+\sigma^{2}
$$

where

$$
\sigma^{2}=\frac{Q-(K-1)}{\sum_{p o p=1}^{K} p_{p o p}-\frac{\sum_{p o p=1}^{K} p_{p o p}^{2}}{\sum_{p o p=1}^{K} p_{p o p}}}
$$

The estimates $v_{\text {pop }}^{\prime}$ are then used to compute the weights $p_{p o p}^{\prime}=1 / v_{p o p}^{\prime}$ and the analysis proceeds as in the fixed-effect model. In Fig. 5, the weights for each population reported on the right of the graphs are the values of $p_{\text {pop }}^{\prime}$ the diamonds represent the value of $\bar{r}$ and the corresponding confidence interval $\left[\bar{r}_{\text {inf }} ; \bar{r}_{\text {sup }}\right]$. 